\title{
Un peu de bois et d'acier: Dasein, Ma e Imagem-Texto: linguagem visual e as significações efêmeras do cotidiano
}

\section{Un peu de bois et d'acier: Dasein, Ma and Image-Text: visual language and the momentaries meanings from daily life}

10.11606/2316-9877.2021.v9i2.160356

\author{
Gilvan Charles Cerqueira Araújo' \\ Secretaria de Educação do Distrito Federal \\ Universidade de São Paulo \\ Faculdade de Filosofia, Letras e Ciências Humanas
}

\begin{abstract}
Resumo
A Nona Arte tem conquistado cada vez mais espaço e importância entre o público em geral e a crítica literária, muito por conta de sua linguagem que mescla o textual ao visual, expandindo as formas de expressão de ações e situações em seus quadros imagéticos. Na obra Un peu de bois et d'acier (Um pedaço de madeira e aço), de Christophe Chabouté, os recortes imagéticos, em quadros sequenciados, trazem consigo a espacialidade servida como plataforma e inspiração, em sua totalidade e singelos detalhes amiúde perpassados por nossa apressada existência. Neste artigo com fins de fomentar um auxílio argumentativo e analítico, utilizar-se-ão os conceitos de Dasein, Ma e Imagem-Texto na obra de Chabouté, explorando as maneiras pelas quais as significações da existência em seu cotidiano são projetadas nos quadros visuais do autor e sua obra.
\end{abstract}

Palavras-chave: Un peu de bois et d'acier. Dasein. Ma. Imagem-Texto. Linguagem Visual. Espacialidade. Cotidiano.

\section{Abstract}

The Ninth Art has earned more and more space and importance in the general public and in the literary criticism, largely because of its language that mixes the textual with

\footnotetext{
1 Professor de Geografia na Secretaria de Estado de Educação do Distrito Federal. Graduação em Geografia pela Universidade Estadual Paulista Júlio de Mesquita Filho (2009). Mestrado em Geografia pela Universidade de Brasília (2013) e doutorado em Geografia pela Universidade Estadual Paulista Júlio de Mesquita Filho (2016). Pós-doutorando em Geografia pela Universidade de São Paulo. E-mail: gcca99@gmail.com. (1) https://orcid.org/0000-0003-42380139.
} 
the visual resources, expanding the forms of expression, actions and situations in their imagery. In Christophe Chabouté's Un peu de bois et d'acier (The park bench), the imagery clippings in sequenced pictures bring with them the spatiality served as a platform and inspiration, in its totality and in simple details, often replete by our hasty existence. Promoting an argumentative and analytical aid by the use of the concepts of Dasein, Ma and Image-Text in Chabouté's work, exploring the ways in which the meanings of existence in their daily life are projected in visual frames of the author's work is the intention of this article.

Keywords: The park bench. Dasein. Ma. Image-Text. Visual Language. Spatiality. Daily Life.

\section{Introdução}

Cada lugar na sua coisa.

(Sérgio Sampaio)

Um pedaço de madeira e aço, traduzido do título original em francês Un peu de bois et d'acier do artista Christophe Chabouté, foi publicada originalmente em 2012 e trazida ao Brasil pela editora Pipoca e Nanquim, em 2018. O formato da obra é em quadrinhos, com os recursos característicos da Nona Arte, apesar da exploração singular dos diálogos (virtualmente inexistentes) em suas páginas. Essa escolha na forma de contar a história encontra seu sentido pelo foco da narrativa, um banco em uma campina, no e ao redor do qual o mundo e pessoas passam e acontecem.

O traço marcante de Chabouté congrega o maneirismo estilístico e visual do autor, mesclando, muitas vezes, um visual realista com simplicidade narratológica em seus quadros. Essa opção de construção textual, narrativa e visual também pode ser encontrada em outros grandes clássicos das histórias em quadrinhos.

Para a composição dos quadros de Un peu de bois et d'acier, o autor optou pelo branco e preto e suas variações de tonalidades, que permitem uma representação mais singela das situações cotidianas ao redor do banco que intitula a obra. Este objeto em questão, o banco de uma praça ou outro lugar qualquer, é escolhido para ser este ponto de circulação do fluxo de pequenas vivências e acontecimentos, animados e inanimados, entrelaçados na tessitura do cotidiano entre presenças e ausências do existir. A silenciosidade também aparece, direta e indiretamente, ao longo das 340 páginas, como um dos elementos centrais da narrativa. Esta quietude é constantemente interrompida 
pelos transeuntes, e não apenas seres humanos, que partilham de sua existência com a localidade e materialidade do banco.

Esta epifania de uma singularidade fática frente à totalidade do mundo é encontrada ao longo de todos os quadros da obra de Chabouté. É a partir desse recorte espacial e material, tendo o banco, e sua constituição de madeira e aço, que o autor evidencia seus propósitos de colocar em exposição um exercício de captação das nuances da vida comum, dos detalhes, das sensações e pequenas durações e restritas extensões.

Por meio dessas breves singularidades existenciais da obra são trazidos para o debate os conceitos de Dasein, Imagem-texto e Ma, por meio dos quais é possível se estabelecer uma articulação com vistas a propor uma forma de interpretação das situações apresentadas a nós na linguagem da Nona Arte de Christophe Chabouté. Tais conceitos, de origens, desenvolvimentos e aplicações, muitas vezes, distantes entre si, colocados em dialogia representam o principal objetivo deste artigo.

\section{1 - A espacialidade e suas essências}

Não há uma única significação ou essência do espaço. A espacialidade, em seu ser, é tão múltipla quantas forem as formas de representá-la, interpretá-la e habitá-la. A construção e reconstrução do espaço, na projeção do habitar em um dos recortes de sua totalidade, torna-se o pico e o vale de seu devir, estando sempre em diferenciações de significância.

A essencialidade da vivência não é geométrica ou mensurável, por isto causa estranheza em sua representação, porque seu algo mais está justamente em não possuir uma qualificação extraordinária do que lhe está próximo: "Escapando às totalizações imaginárias do olhar, existe uma estranheza do cotidiano que não vem à superfície, ou cuja superfície é somente um limite avançado, um limite que se destaca sobre o visível” (CERTEAU, 1994, p. 159). A ordinariedade mundana é residual, compondo a totalização inacabada do existir em seus mínimos detalhes, especialmente nos lugares dos estares no mundo desta existência: "Os relatos de lugares são bricolagens. São feitos com resíduos ou detritos de mundo" (CERTEAU, 1994, p. 174). 
O devir do cotidiano e sua a tentativa de sua captura por parte de Chabouté é admirável, sutil e silencioso. São os múltiplos estares da projeção existencial em inumeráveis circunstâncias de estares, tornando-nos incessante e inevitavelmente indefiníveis, devires móveis do ser-no-mundo, pois, como nos alerta Sartre (1973, p. 35): "[...] em primeira instância, o homem existe, encontra a si mesmo, surge no mundo e só posteriormente se define". O banco da praça de Chabouté, portanto, demonstra alguns dos momentos desses (des)encontros e indefinições da existência, efemeridades cronotópicas do cotidiano ordinário.

A temporalidade, pelas breves passagens de Chabouté, surge em seus quadros como retratos das vivências e projeções de sentido naquela porção do espaço, e não como uma flecha absoluta, apontada apenas numa direção inatingível. A essência fática do espaço é o cotidiano configurado, nessa ocasião, pela presença, ausências e arredores do ente banco. Narrativamente, portanto, é o espaço e espacialidade que tomam frente na obra, e nos guiam em estórias e repartições episódicas de vivências naquela localidade:

O espaço na narrativa, muito além de caracterizar os aspectos físico-geográficos, registrar os dados culturais específicos, descrever os costumes e individualizar os tipos humanos necessários à produção do efeito de verossimilhança literária, cria também uma cartografia simbólica, em que se cruzam o imaginário, a história, a subjetividade e a interpretação. A construção espacial da narrativa deixa de ser passiva - enquanto um elemento necessário apenas à contextualização e pano de fundo para os acontecimentos - e passa a ser um agente ativo: o espaço, o lugar como um articulador da história. A percepção deste pela personagem e seu percurso dão ao leitor uma maior compreensão da constituição de ambos e ampliam as possibilidades de significação do texto (BARBIERI, 2009, p. 105).

E Barbieri (2009) vai além em suas colaborações a respeito da representação do espaço. A autora trabalha, também, com a ideia de conotações, as quais podemos colocar em diálogo com o entendimento das breves significações cotidianas que fazemos, dia após dia, em nossas vidas.

A representação parcial dessas conotações, por meio de um recorte na totalidade fenomênica do ser-no-mundo, normalmente, ocorre por pontos de projeção ontológica em entes específicos: uma parada de ônibus, uma sala de aula, o quintal de uma casa, um diário há muito tempo guardado, uma lembrança 
que insiste em rememorar-se como êmulo presente de nossas rotinas, uma sensação que traz consigo cargas simbólicas das mais diversas, entre outros.

Além das representações do cotidiano e seus sentidos em Un peu de bois et d'acier, encontramos também emanações do ser, entre a enunciação da linguagem pelo ser humano e os objetos que o cercam e situações que vive em outras obras literárias, em prosa ou verso. Essa é a riqueza da diferença ontológica, possível de ser encontrada em meio aos entes, na maior parte das vezes espacialmente representados, que nos formam, significam e singularizam:

Por espaço representado entende-se, principalmente, o caráter que está por trás de sua constituição. Aos espaços físicos e geográficos, às paisagens, às distâncias, às direções, aos objetos colocados na cena, soma-se um estrato de conotações novas, que pode representar, por exemplo, um certo status social da personagem. O espaço representado na obra, enquanto representação, está impregnado de sentidos que possibilitam ao leitor da objetividade da obra e agregar outros caracteres possíveis para o que lhe foi dado a conhecer ao longo da leitura (BARBIERI, 2009, p. 116).

Analiticamente temos, além da primazia pela representação espacial em Un peu de bois et d'acier, também essa colocação da temporalidade em um degrau complementar à espacialidade. O espaço representado eleva-se, em potência e rota de interpretações possíveis da obra de Chabouté (LACEY, 1972; PANKOW, 1988; BACHELARD, 2008; BLANCHOT, 2011; SUZUKI, 2005, 2006). As expressões linguísticas da nona arte, ou seja, os quadros, onomatopeias, closes e segmentações das ações em tiras específicas, vêm no sentido de colaborar com as representações espaciais e seus mosaicos simbólicos.

Observamos na obra de Chabouté os dois caminhos mais comuns para a expressão literária que possuem o espaço como ponto centrípeto de seu desenvolvimento: primeiro caminho, a poesia espacial nata, emanando sentidos para além dos significados e significantes que possam aparecer representados na obra, como trabalhado por Blanchot (2011) e Bachelard (2008); e, em segundo, temos essa mesma espacialidade como suporte narrativo para os eventos que ocorrem durante 0 desenvolvimento da história em questão, aproveitando-se de todos os detalhes possíveis daquele recorte fático em meio à totalidade fenomênica do espaço.

Este último ponto, da espacialidade e sua importância na narrativa pode ser encontrado em autores como Bosi (2000) e Brandão (2013), em concordância com o 
potencial da nona arte, narrativa e imageticamente, como trabalhado por Eco (1976), Cavalcanti (1977), Cagnin (2014), Pontes (2009), Ballmann (2009).

A linguagem do espaço, neste caso, não apenas fortalece a obra, como oferece ao seu conteúdo uma unicidade narrativa e de sustentação do conteúdo textual e de imagens apresentados. Há, sobremaneira, uma expansão do lugar e da historicidade, mais até da espacialidade, em primazia da importância da extensão que a duração, havendo a realidade objetiva trazido para si a força do cotidiano nos quadros temporais dos recortes situacionais apresentados dos sujeitos e demais elementos ali entrecruzados:

Assim, a literatura, o cinema, o mapa, o enigma, a imagem e o romance expandem o campo de experiência e aprendizagem do homem; fazem-no viver situações inesperadas e o projetam para além da historicidade e de seu lugar. Também possibilitam a construção de novas hipóteses, colocam o "objeto" novamente em contato com as diferentes matrizes que conduzem às ações dos sujeitos no espaço, sendo o teor dessas ações perpassado pelos imaginários da ciência e da vida cotidiana. Essas formas de representação levam o homem a sentir e a compreender aspectos que 0 distinguem e 0 aproximam de outras experiências com o mundo, garantidas pelos mecanismos de duplicação imaginária, estratégia essencial do paradigma da cultura para fechar a brecha da incompletude, da insatisfação e da incompreensão da totalidade da realidade "objetiva". Projetamo-nos em personagens, distinguimo-nos deles, amamolos e odiamo-los, como se assim pudéssemos operar formas de aprendizagens não possíveis no mundo vivido pelas contingências socio-históricas (DANTAS, MORAIS, 2018, p. 57).

Nós existenciamos o mundo, colocamos nos mais ínfimos e particulares entes substratos e espessuras do ser (CERTEAU, 1994). Ultrapassamos a denotação, preenchendo a onto-ontologia do mundo por nossas conotações, espessurando cada traço do viver, fornecendo ao trivial o algo a mais de seu acaso momentâneo e localizado. A literatura, e suas diferentes formas de manifestação e representação, nos possibilita traduzir tais singularizações do ser; a junção da imagem e do texto na banda desenhada fortalecem ainda mais este poderio de porta-voz do sentido na linguagem:

Não resta dúvida que unicamente a arte literária teria condições para me favorecer nesse ponto de minha obra; nenhuma outra arte, se porventura eu possuísse os meios exigíveis, me concederia a flexibilidade, a ductilidade com que a literatura, por estear-se na imaginária interna, comunica, ao menos por 
aproximação, o que o autor pretende desnudar sobre uma intuição de tipo imanente, à maneira desta que envolve a aglutinação do existenciador e do objeto de existência (COUTINHO, 1976, p. 183).

Neste texto não será possível um aprofundamento das grandes correntes filosóficas que se debruçaram sobre as nuances do existir e de sua fenomenicidade. No entanto, frisa-se: é a espacialidade que recebe o protagonismo das narrativas da existência, do pensar, do agir, na miríade situacional de um intervalo temporal restrito, como um dia de vivências.

Nossa existência é posicional como diria Eric Dardel e, ao banco de Chabouté foi relegada a função de onto-centrípeto das passagens significativas, mesmo que cheguem a produzir escopos memoriais, dos sujeitos que por ali passam: "Igualmente imaginário é o fato de que, nas relações indicadas por habitar, construir, cultivar, circular a Terra é experimentada como base" (DARDEL, 2011, p. 40). E completa o autor: "Não somente ponto de apoio espacial e suporte material, mas condição de toda "posição" da existência, de toda ação de assentar e de se estabelecer (de poser et de reposer)" (DARDEL, 2011, p. 40).

Essa concepção de base situacional também é utilizada por Simmel (1973), mas alocando-a no conceito de paisagem. A paisagem fornece as provisões das significações cotidianas da existência. Não possuímos, e sequer conseguiríamos, obter todos os recursos necessários, concretos ou abstratos, para a captação de todas as ocorrências situacionais de projeções simbólicas que nos rodeiam; tal condição geraria um rompimento com nossa metafísica da finitude, abarcada e enraizada na cronotopia do existir que nos define, em sua historicidade e geograficidade. O banco de Chabouté não é paisagem, ou seja, espaço simbolizado, ele torna-se paisagem, ou ao menos parte dela, quando singulariza-se nos momentos retratados pelo autor, das geo-grafias de existência emergidas naquele local e instante:

[...] para a paisagem, é justamente essencial a demarcação, o ser-abarcada num horizonte momentâneo ou duradouro; a sua base material ou os seus fragmentos singulares podem, sem mais, surgir como natureza - mas, apresentada como "paisagem", exige um ser-para-si talvez óptico, talvez estético, talvez impressionista, um esquivar-se singular e característico a essa unidade impartível da natureza, em que cada porção só pode ser um ponto de passagem para as forças totais da 
existência. Ver como paisagem uma parcela de chão com o que ele comporta significa então, por seu turno, considerar um excerto da natureza como unidade - o que se afasta inteiramente do conceito de natureza (SIMMEL, 1973, p. 6).

Coloquemos novamente Dardel (2011) em diálogo com as colocações de Simmel (1973) e a simbolização espacial da história de Chabouté. O devir da espacialidade eclode nos lugares, nas paisagens e nas fissuras do ser presentes na diferença ontológica, em circunscrições situacionais de significação dos sujeitos, topofiliando-se a estes lugares e paisagens (TUAN, 1980). Nossa existência é circunstancial e intencional, em contingência de fatos e fenômenos, porque somos aqueles responsáveis por contemplar o sentido, encontrá-lo para vislumbrar sua breve passagem:

Inversamente, o espaço terrestre aparece como a condição de realização de toda realidade histórica, que lhe dá corpo e assinala a cada existente o seu lugar. É a Terra que, podemos dizer, estabiliza a existência. No ritmo da vida, ela traz o lamento de repouso e de abrandamento que modera sua inquietude e sua tensão. Uma calma e um equilíbrio emanam das grandes planícies, das montanhas e do oceano, do trabalho na terra, da vegetação e dos ciclos da vida orgânica. A Terra é, por excelência, para o homem, como destino, a circunstância (circumstare), aquilo que se ergue à sua volta e mantém sua presença como engajamento no Ser. O distante e o próximo, a vertente ensolarada e a vertente sombreada, a fuga horizontal dos rios e dos campos, a vertical dos altos cimos, confirmam a todo instante a existência com sua presença, como espacialização do mundo, emersão acima as coisas. O homem procura a Terra, ele a espera e a chama com todo o seu ser (DARDEL, 2011, p.42).

Essa reflexão sobre a imagem, as representações espaciais, a linguagem e arte emanadas como expressão da liberdade do sentido é que, com frequência, falta aos entes denotativamente colocados como portadores de camadas simbólicas a respeito de alguma especificidade social, histórica, política; como são os casos de alguns patrimônios eleitos na condição de detentores de tais lastros de sentido, o paradoxo de tal situação não poderia ser mais complexo e demandar tamanho fôlego de debate: "O nosso olhar pode jungir os elementos paisagísticos ora neste ora naquele agrupamento, deslocá-los entre si de múltiplas maneiras, deixar variar o centro e os limites" (SIMMEL, 1973, p. 12). A imagem, a representação, o símbolo e o significado são particulares, precisam 
de construções legítimas, que não obedecem às regras ou delimitações normativas de mensuração de sua espessura sígnica, no entanto "[...] a imagem humana determina tudo isto a partir de si, realizou pelas suas próprias forças a síntese à volta do seu centro e, desse modo, delimita-se a si mesma, sem ambiguidade" (SIMMEL, 1973, p. 12).

A configuração da tríplice ótica de interpretação da obra de Chabouté proposta neste artigo possui seus conceitos matrizes: Ma, Dasein e Imagem- Texto. São estes conceitos a serem trabalhados nesse artigo, por meio da espacialidade em suas singularidades fáticas em pequenas e breves exposições da vida cotidiana em banco de um lugar qualquer, encontrável em todos os lugares.

\section{$2-\mathrm{Ma}$}

O conceito de Ma é de origem oriental e, nas palavras de Sinzato (2008), possui a seguinte definição: "A tradução de Ma é espaço, intervalo, e trata, de forma geral, da consciência do espaço que existe entre as coisas. E espaço aqui é definido como algo inscrito no tempo, como instâncias inseparáveis: espaçotempo" (SINZATO, 2008, p. 108). A espacialidade do intervalo, mais do que de vazio, está presente no significado de Ma. O entre-espaços, ou entre coisas e aconteceres também podem ser entendidos como parte da essência da ideia de Ma, ou seja, um intervalo situacional, o repouso entre movimentos de coisas, sujeitos, vivências.

Dessa maneira a ideia de Ma traz consigo o intervalo, o espaço e a contemplação dos sentidos passageiros destas espacialidades: "O Ma, semioticamente, pode ser considerado como um estágio pré-sígnico, pertencente à primeiridade peirciana, isto é, anterior à existência do objeto como fenômeno" (OKANO, 2014, p. 151). Os espaços vazios, passíveis de preenchimentos sígnicos situacionais também estão presentes na definição do conceito de Ma, como o exposto a seguir:

O Ma origina-se da ideia de um espaço vazio demarcado por quatro pilastras no qual poderia haver a descida e a consequente aparição do divino. O espaço seria, assim, o da disponibilidade de acontecer e, como toda possibilidade, o fato poderia concretizar-se ou não. Para se apreender tal concepção, além de abdicar da lógica dual, é necessário também ter em mente 
que a possibilidade de "tudo poder ser" pertence ao campo da continuidade, ao passo que a entrada no reino da existência provoca um deslocamento para a esfera da contiguidade, regida pela sequencialidade. Assim, o aparecimento no mundo como fenômeno cria a descontinuidade dentro de uma múltipla possibilidade de ser, tornando singularidade aquilo que é manifestado e, logo, permitindo a experiência do seu conhecimento (OKANO, 2014, p. 151).

O banco da obra de Chabouté transmite ambas as significações, do Ma e Dasein. No primeiro caso por, constantemente, trazer a representação de um entre coisas, situações, tempos, espaços e indivíduos, um estado de itinerância contínua. Muitos realizadores cinematográficos fazem uso desta ideação do intervalo físico e imaterial desses estares rotineiros das vivências de nossa existência.

Esses diretores exploram justamente a contemplação da espera e dos períodos de passagem, privilegiando os pontos de troca entre eventos e lugares, havendo sempre um pêndulo situacional do movimento e o repouso. E de forma mais ampla, o Ma está presente na cultura japonesa como um todo, na arquitetura, escrita, pintura, dentre outros, em resumo, a valorização do intervalo, do vazio e do entre-coisas está na fonte de sentido desse conceito:

A relação entre o espaço e o tempo para o Ma é muito mais semântica do que sintática, e a semântica contrapõe-se com frequência à sintaxe, caso em que a primeira se ocupa do que algo significa, enquanto a segunda se debruça sobre as estruturas ou padrões formais e espaciais do modo como esse algo é expresso. Dependendo da concepção de significado que se tenha, têm-se diferentes semânticas. A espacialidade Ma está intimamente relacionada ao significado, sendo em busca da transmissão dessa essência do vazio arquitetônico, a primordial característica desse segmento intrínseco a cultura oriental. É o reflexo de que toda a experiência espacial contempla um processo de tempo estruturado e toda fração de tempo dispõe de um estado de espaço real (COUTINHO, 2015, p. 43).

O caráter dialético do Ma encontra-se, dessa forma, inerente à sua constituição dualística:

O vazio está inextricavelmente ligado com a plenitude, (assim como é anterior à plenitude) através de um processo de interiorização e transformação, não é surpreendente, portanto que o conceito de vazio tenha uma considerável importância na linguagem da arte oriental asiática (BRAGUEZ, 2016, p. 27). 
E a mobilidade dos vazios e preenchimentos são assistidos pelo leitor de Un peu de bois et d'acier e, no limite, podemos nos projetar, de igual modo, naquele recorte espaço temporal de significação cotidiana representado pelo banco.

\section{3 - Dasein}

Já a ideia de dasein possui raiz germânica, especificamente da obra do filósofo Martin Heidegger (2008; 2013). O verbete é formado pela junção de dois termos da e sein, o primeiro significa aí e o segundo ser, sendo traduzido para o português como ser-aí ou presença, a depender da edição ou tradução dos trabalhos do filósofo alemão.

Pode-se compreender também dasein como 0 ser manifestado acontecido, situado, delimitado faticamente, em outras palavras, a essência do ente em (des)velamento em seus estares. Ser-aí também é compreendido como a abertura do existir humano, por entre o qual, o ser encontra seu caminho de manifestação sendo-e-estando-no-mundo, localizado no limiar entre a imanência e essência, e as nuances da diferença ontológica.

O ser humano, com sua capacidade de enunciação dos sentidos emanados nos demais entes, e essa expressão ontológica é alcançada pela arte, tentando captar, mesmo que temporariamente, as singularizações de sentido dos entes (GMEINER,1998). Estes são alguns dos pontos de reflexão de Martin Heidegger sobre a facticidade, o cotidiano e singularizações de sentido que permeiam os entes:

Consideremos a cotidianidade mais absoluta: ao demorar-se em casa, ao encontrar-se num quarto, onde finalmente se encontra algo assim como "uma mesa"! Como isso ou aquilo vem à mesaencontro? Trata-se de uma coisa no espaço; enquanto tal coisa espacial é também algo material. Pesa tanto, tem tal cor, tal forma, a tampa é quadrada ou redonda; mede tanto de altura, tanto de largura, sendo sua superfície suave ou grossa. É possível desfazer a coisa em pedaços, é possível queimá-la ou destruí-la de qualquer outra maneira. Essa coisa espacial e material, que se apresenta de tal maneira segundo os diferentes aspectos possíveis da sensibilidade, mostra-se sempre em sua "ocorrência" apenas a partir de um lado determinado, de tal modo que o aspecto desse lado se funde continuamente com os dos outros lados, prefigurados graças à configuração espacial da coisa; e assim com todos e cada um dos lados (HEIDEGGER, 2013, p. 90). 
Em complemento a essas colocações, o autor ainda se debruça sobre os objetos e suas objetivações: "Os objetos - os entes objetivados - também não são, porém, aquilo em direção ao que se dá a ultrapassagem." E a posição situacional do dasein por meio do seu ser em constante manifestação no mundo, sendo-no-mundo ultrapassa, preenche e dá aos entes suas espessuras de significado(s): "O que é ultrapassado é precisa e unicamente o ente mesmo, e, na verdade, cada ente que pode tornar-se ou já está desvelado para o ser-aí; por conseguinte, também e justamente o ente que "ele mesmo" é enquanto existe" (HEIDEGGER, 2008, p. 150).

O esforço empreendido nessa delimitação teórica e epistemológica do ente se dá também ao ser, mais precisamente no ser-aí, a presença humana no mundo: "A proposição: o ser-aí fático é em um mundo (ocorre entre outros entes) se revela como uma tautologia que nada diz. A enunciação: faz parte da essência do ser-aí o fato de estar no mundo (de também ocorrer "ao lado" de outros entes) se mostra como falsa." E ainda completa o filósofo alemão que é o ser o possuidor e também elo de comunicação e expressão da diferenciação ontológica, extraindo da imanência sua transcendentalização: "A tese: da essência do ser-aí como tal faz parte o ser-no-mundo, contém o problema da transcendência" (HEIDEGGER, 2008, p. 153).

Quando colocamos estas conceituações de Heidegger nas imagens e expressões sígnicas na obra de Chabouté, percebemos a existência de ente focalizado, no caso o banco (a facticidade), atravessado, especializado e significado por diferentes presenças do ser-aí projetados no mundo em seu momento de interação, mesmo que efêmera, naquele ponto específico da espacialidade que atravessa seu cotidiano.

A palavra, o texto e a imagem, nessa trilha expositiva, nos apresentam "singularidades do ser": "A "palavra" é palavra "do" Ser ("Voz" toante do silêncio silente. Silêncio: Negação (domínio) do a-bismo da a-propriação do produto. Portanto, o que podemos encontrar na obra de Chabouté é uma verdadeira topologia do ser como trabalhado por Gmeiner (1998), Pádua (2005), Silva (2000) e Martins (2007), além de dar ao espaço o aspecto de grafia existencial, poetizando-o esteticamente para o seu recorte fático, por meio do banco da 
praça. Espaço, lugar, linguagem e facticidade confluem-se, em possibilidades de significação do cotidiano:

A abordagem heideggeriana das questões relativas a espaço e lugar começa a tomar forma a partir da noção de espacialidade fática (faktischen Räumlichkeit) - delineada nos capítulos terceiro e quarto da segunda parte de Ontologie $34-$, que se apresenta com nitidez quando o autor se propõe investigar de que maneira, a partir de determinadas situações concretas, inseridas numa cotidianidade imediata, se nos apresenta fenomenologicamente o mundo (PÁDUA, 2005, p. 38).

As passagens da obra de Chabouté trazem essa singularização espacial, para que seja possível a retração desses significados da vida comum em sua mundaneidade: "Mundanidade e desencobrimento constituem um único e mesmo fenômeno: o da compreensão mesma do Dasein, imerso em sua vida fática." (PÁDUA, 2005, p. 38). A indefinição do sentido da existência, suscitado por Sartre (1973), ganha outra projeção, desta vez no sentido das pequenas ações, escolhas e partilhas do dia-a-dia, já que essa mundaneidade cotidiana: "[...] por sua vez, se efetiva na rede de remissões que constitui o mundo, onde cada coisa remete à outra, dotado desse encontro de significatividade (Bedeutsamkeit ) (PÁDUA, 2005, p. 38).

A imagem e recorte fático completam-se, por meio do traço de Chabouté, tirando, da silenciosidade rotineira, pequenos momentos, telescópicas focalizações, significativas passagens do devir em seus estares, diferentes formas de ser-no-mundo. O entremeio, a pausa e a contemplação daquela situação corriqueira se mostram, transformam-se em fenômeno, transcendentalizam-se em relação ao seu redor, ao menos por um instante: "Mas nessa negação revela-se em sua recusa - como silêncio, como 'entremeio' (Inzwischen), como Da (ali). Só agora proximidade da essência - e nenhuma 'renúncia”' (HEIDEGGER, 2015, p. 60).

\section{4 - Imagem-texto}

O Ma e o dasein, trazidos anteriormente, e encontrados em Un peu de bois et d'acier carregam consigo a mesclagem entre a linguagem, o contexto e texto, como referido por Halliday, Hasan (1989), por meio da Nona Arte de Chabouté, 
de modo a dar à imagem maior espessura, um algo a mais, que suplanta os limites concretos do objeto ali posto ou disposto.

Há uma verdadeira epifania da facticidade presente em um determinado intervalo temporal ou extensão espacial que, comumente, acabam por congregar em si diferentes sentidos por aqueles que fazem uso, visualizam, contemplam ou partilham da existência deste ente específico. Chabouté faz essas digressões fenomenológicas por meio do banco, em sua constituição de madeira e aço, e a imagem-texto, como linguagem visual vai ao encontro dessa proposta do autor.

E encontramos também, nesse exemplar da Nona Arte, uma expressão da imagem-texto, no sentido de elevação do significante, o traço desenhado em cada quadro, para uma significação que suplanta o apresentado em cada seção e foco da obra. A forma, dessa maneira, não apenas oferece ao conteúdo seu arranjo de significância como também subjaz a potência de interpretação presente em cada detalhe, ângulo, contexto e textura imagética, ou seja, tentativas do poeta-visual em captar a significação daquele momento específico, o detalhe inaudível ou quase inapreensível da mundaneidade fugidia:

Todas as nossas versões do real - silogismos, descrições, fórmulas científicas, comentários de ordem prática, etc. — não recriam aquilo que pretendem exprimir. Limitam-se a representá-lo ou descrevê-lo. Se vemos uma cadeira, por exemplo, percebemos instantaneamente sua cor, sua forma, os materiais com que foi construída, etc. A apreensão de todas essas características dispersas não é obstáculo para que, no mesmo ato, nos seja dado o significado da cadeira: o de ser um móvel, um utensílio. Mas, se queremos descrever nossa percepção da cadeira, teremos de ir aos poucos e por partes: primeiro sua forma, depois sua cor, e assim sucessivamente até chegar ao significado. No curso do processo descritivo foi se perdendo pouco a pouco a totalidade do objeto. A princípio a cadeira foi apenas forma, mais tarde uma certa espécie de madeira, e finalmente puro significado abstrato: a cadeira é um objeto que serve para sentar. No poema a cadeira é uma presença instantânea e total, que fere de um golpe a nossa atenção. O poeta não descreve a cadeira: coloca-a diante de nós (PAZ, 1982, p. 132).

As topologias do ser textualizam-se e tornam-se imagens pelas lentes de Chabouté, pois como nos lembra Gomes (1997, p. 25): "A descrição simples da forma não pode dar conta de todos os significados e todas as práticas sociais." Então, o que temos não são apenas imagens do cotidiano, mas sim sentido do 
sujeito em sua potência máxima, que é seu pensar, caminhar, partilhar, falar ou calar-se enfim, ser-no-mundo.

Como argumentam Foucault (2006) e Coutinho (1976) o lugar, seja-o em heterotopia de significação ou de confluência solipsista será sempre o ponto ao qual a vivência irá se pautar em seu existir. Neste sentido, nota-se que a linguagem da Nona Arte, em dialogia inerente entre a imagem e o texto permite que essa referência espacial da existência seja explorada em seu potencial máximo de representação.

São imagens carregadas de linguagem, grafias, textualidades, eclodem em significações, ultrapassam sua própria fonte de manifestação linguística, seja escrita, visual, sonora, formam-se híbridos abertos, carregados de possibilidade de escrituração onto-ontológica: "[...] a tendência a designar por 'escritura' tudo isso e mais alguma coisa: não apenas os gestos físicos da inscrição literal, pictográfica ou ideográfica, mas também a totalidade do que a possibilita" (DERRIDA, 2017, p. 10-11).

Espacialidade do texto e textualidade do espaço, dualidade imanente e pulsante quadro a quadro da história do banco de madeira e aço. A força da obra está na ausência (a negação) em primeiro plano representada pelo banco na praça e, ao longo das imagens-textuais, os momentos de preenchimento desta ausência pelos transeuntes daquela localidade. Essa concepção da ideia do texto, de forma expansiva e múltipla, em suas diferentes linguagens e expressões também é trabalhada por Barthes (2004): para esse autor, o texto não possui fechamento, é um constante aberto, passagem aberta aos que nele e por ele se aventuram:

O texto é plural. Isso não significa apenas que tem vários sentidos, mas que realiza o próprio plural do sentido: um plural irredutível (e não apenas aceitável). O Texto é coexistência de sentidos, mas passagem, travessia; não pode, pois, depender de uma interpretação, ainda que liberal, mas de uma explosão, de uma disseminação. O plural do Texto deve-se, efetivamente, não à ambiguidade de seus conteúdos, mas ao que se poderia chamar de pluralidade estereográfica dos significantes que o tecem (etimologicamente o texto é um tecido) (BARTHES, 2004, p. 70).

Esta tessitura e espessura do texto referenciados, por Barthes (2004), são encontradas por Chabouté no cotidiano e a facticidade, representadas ôntica e 
ontologicamente pelo banco e, também, figuram como núcleos agregadores de complexa transposição para expressões e representações pelas linguagens artísticas.

Talvez, por essa espessura considerável de elementos, variáveis e imensurabilidade dos aspectos de particularização dos entes, escolhe-se, com frequência, um objeto com o intuito de tentar trazer para fora sua potência de síntese de significância em algum contexto específico.

Essa escala reduzida, mínima, de uma cor, sensação, objeto ou lembrança é encontrada na linguagem poética, prosaica, escultural, fotográfica, teatral, sempre tendo como direção de sua significação a existência. A composição, justaposição ou emaranhado dessas vivências comporão o cotidiano (CERTEAU, 1994), a paisagem (BESSE, 2006) e os lugares (DARDEL, 2011) pelos quais a facticidade cotidiana eclode na efemeridade temporal dessas miríades situacionais do devir mundano.

\section{Conclusão: significações efêmeras do cotidiano}

A espacialidade se projeta ontologicamente, fornecendo à objetividade sua espessura subjetiva, simbólica, emocional e memorial. O banco de Chabouté possui essas características, pois tantas quantas forem as vezes que alguém por ali passar, interagir ou registar um momento de suas existências, tantas outras serão as representações simbólicas cristalizadas por esses momentos.

Os conceitos aqui discutidos como Ma, dasein e imagem-texto foram selecionados no sentido de contribuir com a argumentação proposta. O cotidiano é facticidade em preenchimento constante da fenomenicidade que nos atravessa. Essas pequenas práticas, dizeres, situações, fazeres e esperas não apenas se exteriorizam, mas também fruem no interior da existência, fornecendo-Ihe camadas de brevidades temporais e espaciais.

Os objetos, o recorte fático, seja ele qual for, e Chabouté fez sua escolha num pedaço da totalidade feita de aço e madeira, nos cercam e servem de inspiração aos poetas, artistas, pintores, escultores, músicos, todos os arautos da arte em suas múltiplas linguagens. O que Chabouté nos oferece com seu banco em uma praça qualquer é a captação, nesse incognoscível entremeio de coisas, esperas, chegadas e partidas, lugares, temporalidades, sensações, 
pensamentos, emoções e pessoas. Naquele banco, há um repouso e pausa, frenagem contemplativa e despercebida do devir, em um arranjo material e imaterial de aço e madeira.

\section{Referências}

BACHELARD, Gaston. A poética do espaço. 2. ed. São Paulo: Martins Fontes, 2008.

BALLMANN, Fábio. A Nona Arte: história, estética e linguagem de quadrinhos. Dissertação (Mestrado Ciências da Linguagem) - Universidade do Sul de Santa Catarina, Tubarão, 2009.

BARBIERI, Cláudia. Arquitetura literária: sobre a composição do espaço narrativo. In: BORGES FILHO, Ozíris; BARBOSA, Sidney. (Org.). Poéticas do espaço literário. São Carlos: Claraluz, 2009, v. 01, p. 105-126.

BARTHES, Roland. O rumor da língua. São Paulo: Martins Fontes, 2004.

BESSE, Jean-Marc. Ver a Terra: seis ensaios sobre paisagem e geografia. São Paulo: Perspectiva, 2006.

BLANCHOT, Maurice. O espaço literário. Rio de Janeiro: Rocco, 2011.

BOSI, Alfredo. O ser e o tempo da poesia. São Paulo: Companhia das Letras, 2000.

BRAGUEZ, Joana Rita Cerieira. Do vazio ao sublime, percursos estéticos. Tese (Doutoramento em Artes) - Colégio das Artes, Universidade de Coimbra. Coimbra, 2016.

BRANDÃO, Luis Alberto. Teorias do espaço literário. São Paulo: Perspectiva; Belo Horizonte: FAPEMIG, 2013.

CAGNIN, Antonio Luiz. Os quadrinhos: um estudo abrangente da arte sequencial: linguagem e semiótica. São Paulo: Criativo, 2014.

CAVALCANTI, Ionaldo de Andrade. O mundo dos quadrinhos. São Paulo: Símbolo, 1977.

CERTEAU, Michel. A invenção do cotidiano. Petrópolis: Vozes, 1994. v.1: artes de fazer.

CHABOUTÉ, Christophe. Um pedaço de madeira e aço. São Paulo: Pipoca e Nanquim, 2018.

CHABOUTÉ, Christophe. Entrevista ao canal Comix Zone. Disponível em: https://www.youtube.com/watch?v=5Mfo1 56T4s. Acesso em: 15 fev. 2019.

COUTINHO, Evaldo. O lugar de todos os lugares. São Paulo: Perspectiva, 1976.

COUTINHO, Walkyria Tsutsumi Ferreira. O conceito Ma: o conceito Ma na conformação de espaços em Tadao Ando. Dissertação (Mestrado em Artes) - Centro de Artes, Universidade Federal de Pernambuco, Recife, 2015.

DANTAS, Eugênia Maria; MORAIS, Ione Rodrigues Diniz. Geografia: entre o sensível e o científico, um conhecimento complexo. Geographia, Rio de Janeiro, Universidade Federal Fluminense, v. 20, p. 51-59, 2018. 
DARDEL, Eric. O homem e a terra: natureza da realidade geográfica. São Paulo: Perspectiva, 2011.

DERRIDA, Jacques. Gramatologia. São Paulo: Perspectiva, 2017

ECO, Umberto. Apocalípticos e integrados. São Paulo: Perspectiva, 1976.

FOUCAULT, Michel. Outros espaços. In: FOUCAULT, Michel. Estética: literatura e pintura, música e cinema. 2.ed São Paulo: Forense Universitária, 2006.

GMEINER, Conceição Neves. Morada do Ser: uma abordagem filosófica da linguagem na leitura de Martin Heidegger. Santos: Leopoldianum, 1998.

GOMES, Paulo César da Costa. Geografia fin-de-siècle: o discurso sobre a ordem espacial do mundo e o fim das ilusões. In: CASTRO, Iná Elias de; CORRÊA, Roberto Lobato; GOMES, Paulo César (Org.). Explorações geográficas: percursos no fim do século. Rio de Janeiro: Bertrand Brasil, 1997. p. 13-42.

HALLIDAY, Michael Alexander Kirkwood; HASAN, Ruqaya. Language, context and text. aspects of language in a social semiotic perspective. Oxford: Oxford University Press, 1989.

HEIDEGGER, Martin. Marcas do caminho. Petrópolis: Vozes, 2008.

HEIDEGGER, Martin. Ontologia: hermenêutica da facticidade. Petrópolis: Vozes, 2013.

HEIDEGGER, Martin. Sobre a essência da linguagem: a metafísica da linguagem e a vigência da palavra. Petrópolis: Vozes, 2015.

LACEY, Hugh. A linguagem do tempo e do espaço. São Paulo: Perspectiva, 1972.

MARTINS, Elvio. Geografia e Ontologia: o fundamento geográfico do ser. GEOUSP Espaço e Tempo, São Paulo, n. 21, p. 33-51, 2007. Disponível em: http://www.revistas.usp.br/geousp/article/view/74047. Acesso em: 18 fev. 2019.

OKANO, Michiko. Ma: a estética do 'entre'. Revista USP, v. 1/2, p. 150-164, 2014.

PÁDUA, Ligia Teresa Saramago. A "Topologia do ser": lugar, espaço e linguagem no pensamento de Martin Heidegger. Tese (Doutorado em Filosofia) - Departamento de Filosofia, PUC, Rio de Janeiro, 2005.

PANKOW, Gisela. O homem e seu espaço vivido: análises literárias. Campinas/SP: Papirus, 1988.

PAZ, Octávio. O arco e a lira. Rio de Janeiro: Nova Fronteira, 1982.

PONTES, Gabriel Lopes. As histórias em quadrinhos como Bela-Arte. Dissertação (Mestrado em Artes Visuais) - Escola de Belas Artes, Universidade Federal da Bahia, 2009.

SARTRE, Jean Paul. O Existencialismo é um humanismo. São Paulo: Nova Cultural, 1973.

SILVA, Armando Correa da. A aparência, o ser e a forma: geografia e método.

GEOgraphia, Rio de Janeiro, v. 2, n. 3, 2000. Disponível em:

https://periodicos.uff.br/geographia/article/view/13372. Acesso em: 25 mar. 2019. 
SIMMEL, Georg. A metrópole e a vida mental.. In: VELHO, Otávio Guilherme. O fenômeno urbano. Rio de Janeiro: Zahar Editores, 1973.

SINZATO, Alice Yumi. MA, o vazio intervalar. Revista Ciclos, Florianópolis, v. 2, n. 4, ano 2, p. 103-115, fev. 2015.

SUZUKI, Julio Cezar. Geografia e Literatura: uma leitura da cidade na obra poética de Paulo Leminski. Revista da ANPEGE, Fortaleza, v. 2, p. 114-142, 2005. Disponível em:

http://www.anpege.org.br/revista/ojs-2.4.6/index.php/anpege08/article/view/87. Acesso em: 10 fev. 2019.

SUZUKI, Julio Cezar. O espaço da narrativa: uma leitura de "preciosidade". Revista do Departamento de Geografia (USP), v. 19, p. 55-68, 2006. Disponível em: http://www.revistas.usp.br/rdg/article/view/47252. Acesso em: 10 jan. 2019.

TUAN, Yi-Fu. Topofilia: um estudo da percepção, atitudes e valores do meio ambiente. São Paulo: DIFEL, 1980. 